\title{
Diseminasi Kebijakan Pendidikan melalui Program Merdeka Belajar - Kampus Merdeka Pada Perguruan Tinggi Muhammadiyah di Makassar Indonesia
}

\author{
Nasrulhaq ${ }^{1}$, Ahmad Harakan ${ }^{2}$, Syukri $^{3}$, Sitti Rahmawati Arfah ${ }^{4}$, Nur Khaerah ${ }^{5}$, \\ Nurbiah Tahir ${ }^{6}$, Nur Wahid ${ }^{7}$ \\ ${ }^{1234567}$ Fakultas Ilmu Sosial dan Ilmu Politik, Universitas Muhammadiyah Makassar \\ 22ahmad.harakan@unismuh.ac.id
}

\begin{abstract}
This research discusses the dissemination of education policy by looking at the responses and insights of students, lecturers, and education staff at the University of Muhammadiyah Makassar towards the Merdeka Belajar-Kampus Merdeka (MBKM). The biggest challenge in implementing educational policies in higher education is the percentage of understanding of the academic community and their readiness to implement education policy packages implemented by the government. In this study, a qualitative method was used by using a case study at the University of Muhammadiyah Makassar. The data was obtained from the results of a survey to students, lecturers, and education staff conducted by the MBKM Grant Team of the University of Muhammadiyah Makassar through a survey platform and survey questions facilitated by the Ministry of Education and Culture of the Republic of Indonesia starting on 18-22 December 2021. The results of the survey processed using the Nvivo application. There have been various responses regarding the Independent Learning-Kampus Merdeka Program and it can be concluded that the dissemination of the MBKM policy still needs to be maximized, because there are still many educators and students who do not know the nature of the policy.
\end{abstract}

\section{Keywords: Policy Dissemination; Education Policy; College}

\begin{abstract}
Abstrak
Penelitian ini membahas tentang diseminasi kebijakan pendidikan dengan melihat respon dan wawasan mahasiswa, dosen, dan tenaga kependidikan di Universitas Muhammadiyah Makassar terhadap program Merdeka Belajar-Kampus Merdeka (MBKM). Tantangan terbesar dalam pelaksanaan kebijakan pendidikan di perguruan tinggi adalah prosentase pemahaman civitas akademika dan kesiapannya dalam mengimplementasikan paket kebijakan pendidikan yang dilaksanakan oleh pemerintah. Dalam penelitian ini, digunakan metode kualitatif dengan menggunakan studi kasus pada Perguruan Tinggi Muhammadiyah di Kota Makassar. Data didapatkan dari hasil survei kepada mahasiswa, dosen, dan tenaga kependidikan yang dilakukan oleh Tim Hibah MBKM Universitas Muhammadiyah Makassar melalui platform survei dan pertanyaan survei yang difasilitasi oleh Kementerian Pendidikan dan Kebudayaan Republik Indonesia yang dimulai pada tanggal 18-22 Desember 2021. Hasil survei tersebut diolah menggunakan aplikasi Nvivo. Ada beragam respon terkait Program Merdeka BelajarKampus Merdeka dan dapat disimpulkan bahwa diseminasi kebijakan MBKM masih perlu dimaksimalkan, karena masih banyak tenaga pendidik dan mahasiswa yang belum mengetahui hakikat dari kebijakan tersebut.
\end{abstract}

Kata Kunci: Diseminasi Kebijakan; Kebijakan Pendidikan; Perguruan Tinggi 


\section{Pendahuluan}

Praktik pendidikan pada perguruan tinggi di Indonesia terkendala pada konektivitas kebijakan pemerintah dengan tantangan yang dihadapi. Seringkali kebijakan pendidikan terbaru diterapkan setelah perguruan tinggi menghadapi masalah. Padahal pembahasan pendidikan dalam ranah kebijakan merupakan topik yang membutuhkan perhatian serius dari masyarakat dan tentunya pemerintah (Soeprapto, 2013). Dari sudut pandang sosial dan masyarakat, pendidikan dapat dianggap sebagai salah satu jenis perubahan budaya sebagai landasan, agar kehidupan masyarakat tetap lestari, atau dengan kata lain masyarakat memiliki nilai-nilai budaya yang diwariskan kepada generasi berikutnya (Harakan, 2017).

Secara individual, pendidikan mengandung pengertian adanya pengembangan pada peluang dan potensi terpendam, serta mengangkatnya untuk dipoles sehingga bersinar dan memberi pencerahan kepada manusia (Ningrum, 2016). Magnum Opus peradaban suatu bangsa adalah wawasan dan transfer informasi sebagai komponen peningkatan kualitas manusia dan pembinaan lingkungan kritis, berorientasi solusi, dan positif. Meskipun demikian, dalam dunia politik, kebijakan, dan otoritas, suatu negara memegang kunci keberhasilan transformasi, khususnya di bidang pendidikan yang terkait dengan konteks perkembangan demokrasi dan desentralisasi di Indonesia. (Sarnoto, 2013).

Politik kebijakan pendidikan dalam merespon beragam isu seperti Industrial Revolution 4.0, era Society 5.0, hingga kedigdayaan Metaverse telah menggodok paket kebijakan dengan menghadirkan program Merdeka Belajar dan Kampus Merdeka yang diperuntukkan untuk Perguruan Tinggi. Kampus Merdeka pada hakikatnya merupakan konsep baru yang memberikan kemandirian mahasiswa untuk menempuh pendidikan di bangku perkuliahan (Leuwol et al., 2020; Siregar, Sahirah, \& Harahap, 2020). Gagasan ini dibangun di atas gagasan sebelumnya, Merdeka Belajar. Konsep Kampus Merdeka pada dasarnya merupakan inovasi pembelajaran untuk memperoleh pendidikan yang unggul (ARIFIN \& MUSLIM, 2020; Sopiansyah \& Masruroh, 2022).

Perguruan Tinggi memiliki kebebasan otonomi di bawah Kebijakan Merdeka Belajar -Kampus Merdeka. Mengubah pandangan tentang pendidikan agar lebih mandiri dengan budaya belajar kreatif. Pemberlakuan program ini mendorong pembelajaran perguruan tinggi menjadi lebih mandiri dan adaptif (Sopiansyah \& Masruroh, 2022). Program ini mencakup sembilan jenis kegiatan pembelajaran: pertukaran mahasiswa, bantuan mengajar di satuan pendidikan, penelitian, magang, proyek kemanusiaan, kegiatan wirausaha, studi mandiri, pembangunan desa, dan bela negara. (Mariati, 2021).

Meski kebijakan ini sarat pada kemandirian dan keadaptifan sebuah perguruan tinggi dengan beragam program dalam melaksanakan pembelajaran, namun tantangan berikutnya adalah diseminasi kebijakan Merdeka Belajar - Kampus Merdeka terhadap mahasiswa, dosen, dan tenaga pendidik di perguruan tinggi. Penelitian terdahulu maupun artikel yang telah diterbitkan yang mengkaji tentang Merdeka Belajar-Kampus Merdeka antara lain dibahas oleh Siregar et al., (2020) dengan menitikberatkan pada diskusi Merdeka Belajar-Kampus merdeka secara konseptual dalam menghadapi era Industrial Revolution 4.0. Sedangkan Sopiansyah \& Masruroh (2022) mengkaji implementasi Program Merdeka Belajar-Kampus Merdeka dalam ranah konseptualisasi pada kurikulum di perguruan tinggi. Selain Siregar et al., (2020) dan Sopiansyah \& Masruroh (2022), peneliti lainnya seperti Saleh (2020) memotret efektivitas pelaksanaan program Merdeka Belajar-Kampus Merdeka di saat eskalasi pandemi Covid-19 belum terkendali.

Merespon problematika dan serangkaian penelitian terdahulu tentang Program Merdeka Belajar-Kampus Merdeka, maka penelitian ini lebih berfokus pada dinamika dan wawasan civitas akademika Universitas Muhammadiyah Makassar terhadap diseminasi 
kebijakan pendidikan melalui program Merdeka Belajar - Kampus Merdeka yang telah terlaksana dimulai pada tahun 2020 hingga kini.

\section{Metode}

Kajian diseminasi kebijakan ini menggunakan pendekatan kualitatif melalui studi kasus pada Perguruan Tinggi Muhammadiyah di Kota Makassar. Perguruan Tinggi Muhammadiyah yang dimaksud adalah Universitas Muhammadiyah Makassar. Studi kualitatif melibatkan eksplorasi dan pemahaman pada problematika sosial.

Studi kualitatif mengarah pada perlunya batasan-batasan atas dasar fokus yang muncul sebagai permasalahan dalam suatu penelitian. Oleh karena itu, penelitian ini berfokus pada Respon civitas akademika pada diseminasi kebijakan Program Merdeka Belajar dan Kampus Merdeka di Universitas Muhammadiyah Makassar. Data didapatkan dari hasil survei kepada mahasiswa, dosen, dan tenaga kependidikan yang dilakukan oleh Tim Hibah MBKM Universitas Muhammadiyah Makassar melalui platform survei dan pertanyaan survei yang difasilitasi oleh Kementerian Pendidikan dan Kebudayaan Republik Indonesia dan dimulai pada tanggal 18-22 Desember 2021.

Analisis data mengacu pada alur kegiatan yang digunakan oleh akademisi yaitu dengan mengumpulkan data melalui survei daring, penyesuaian data dengan teknik reduksi, display, dan menentukan kesimpulan atau verifikasi. Selanjutnya, tim penelitian mengadakan Focus Group Discussion terbatas dengan akademisi dan pakar untuk membahas data yang diperoleh untuk penarikan kesimpulan. Penelitian ini juga menggunakan analisis data kualitatif dengan bantuan program komputer Nvivo 12 Plus. Penerjemahan data melibatkan penggunaan Nvivo 12 Plus sebagai alat analisis kualitatif yang menerjemahkan data melalui beberapa tahap yaitu membuat proyek baru, lalu menyusun dokumen, mengkode data, melakukan analisis, serta perbandingan. Penggunaan aplikasi ini sebagai alat bantu untuk mengolah dan memvisualisasikan data dengan lebih atraktif.

\section{Hasil dan Pembahasan}

Perencanaan, proses pembelajaran, penilaian, dan evaluasi pembelajaran merupakan bagian dari model Pengembangan Kurikulum yang berpedoman pada kebijakan MBKM (Baharuddin, 2021). Program MBKM memberikan fleksibilitas dan otonomi lembaga pendidikan dengan menghilangkan birokratisasi kampus, menghilangkan birokrasi yang rumit antara mahasiswa, tenaga pendidik, dan dosen, serta memungkinkan mahasiswa untuk memilih bidang minatnya. Keunggulan program ini tidak semata-mata tentang sembilan program dengan hak belajar tiga semester di luar program studi. Adanya kemudahan pembukaan program studi baru, perubahan sistem akreditasi perguruan tinggi, lalu kemudahan perguruan tinggi negeri menjadi PTN berbadan hukum menjadi patron penting pihak pemerintah menginfiltrasi kebijakan dalam program-program perguruan tinggi.

Kampus merdeka adalah jenis pembelajaran di perguruan tinggi yang otonom dan fleksibel dalam rangka menumbuhkan budaya belajar yang inovatif, tidak terbatas, dan berpusat pada siswa. Perguruan tinggi sudah seharusnya berkomitmen untuk mewujudkan dan melaksanakan Program MBKM sebagaimana yang ditetapkan Permendikbud RI Nomor 3 Tahun 2020, serta yang dijelaskan dalam Buku Panduan Merdeka Belajar Kemendikbud RI (Mariati, 2021). Keberhasilan program MBKM memerlukan diseminasi kebijakan untuk mempermudah seluruh pihak memahami tujuan dari Kebijakan Merdeka Belajar-Kampus Merdeka, penyebaran informasi tentang MBKM yang ditujukan kepada kelompok target (Dosen, Tenaga Pendidik, dan Mahasiswa) agar kiranya timbul kesadaran untuk menerima dan akhirnya menerapkan program tersebut dengan baik. 


\section{Pemahaman Dosen dan Mahasiswa tentang Kebijakan MBKM}

Dosen dan Mahasiswa merupakan aktor utama dalam penerapan kebijakan Merdeka Belajar-Kampus Merdeka (MBKM), pemahaman tentang kebijakan ini sangat dibutuhkan untuk keberhasilan program MBKM. Memahami kebijakan MBKM sangat penting karena Program MBKM telah memberikan keleluasan bagi program studi dalam menjalankan kurikulum yang fleksibel, luwes dan mudah diikuti dengan adanya perubahan dan perkembangan zaman serta teknologi informasi dan komunikasi. MBKM juga membantu terwujudnya sinergi program studi melalui kerjasama dengan pihak lain untuk memastikan proses pembelajaran berjalan sesuai dengan target yang telah ditentukan (Krisnanik, Saphira, \& Indriana, 2021). Melalui diseminasi kebijakan MBKM akan mempermudah dosen dan mahasiswa mendapatkan pemahaman tentang program Merdeka Belajar-Kampus Merdeka.

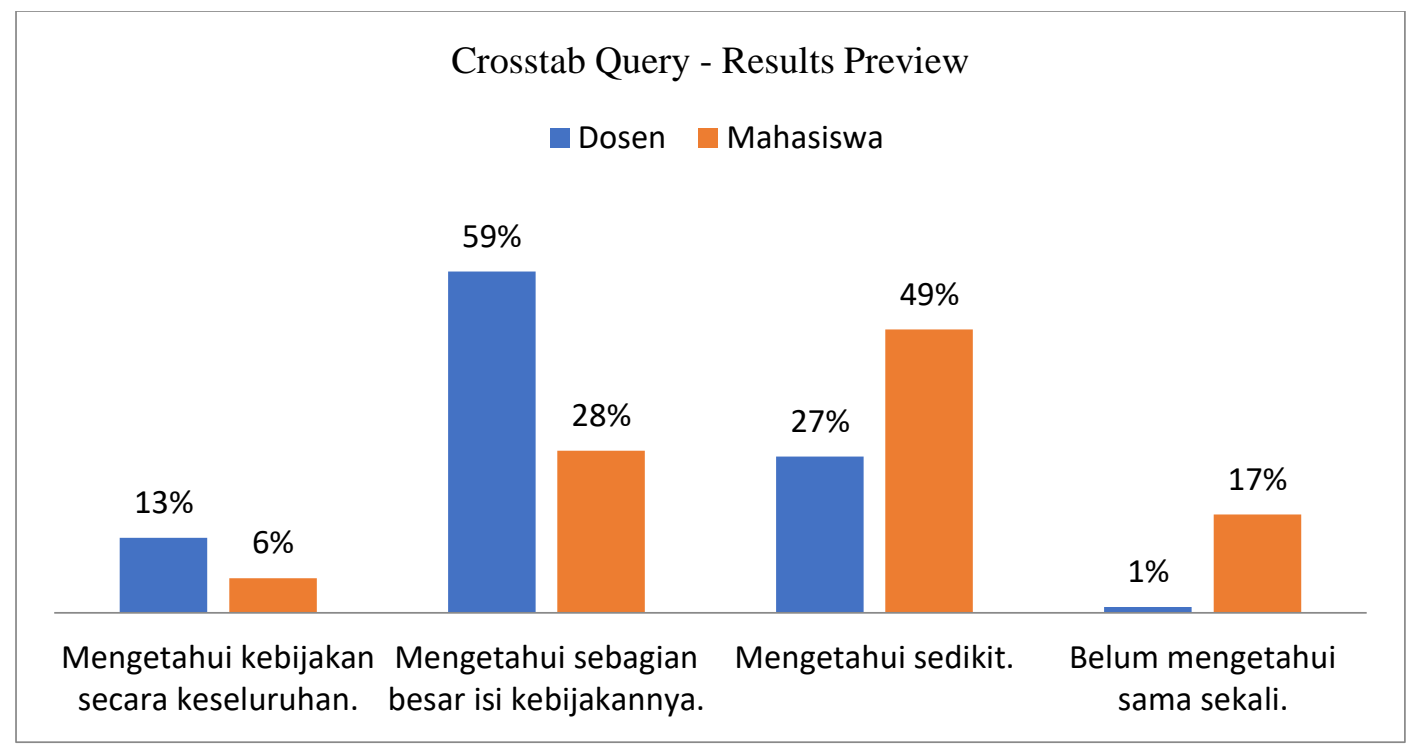

Gambar 1. Pemahaman Dosen dan Mahasiswa tentang Kebijakan MBKM Sumber: Data Diolah oleh Penulis (2021)

Hasil analisis melalui nvivo pada gambar 1 ditemukan bahwa pengetahuan dosen tentang kebijakan MBKM lebih besar dibandingkan mahasiswa, dosen sebagai tenaga pengajar lebih mengetahui sebagian besar isi kebijakan MBKM dengan presentase 59\% dan mahasiswa hanya 28\%. Pemahaman dosen tentang MBKM memiliki andil besar terhadap keberhasilan MBKM, tanpa peran dari Dosen, proses pembelajaran yang baik di luar program studi sesuai yang diharapkan dapat sulit tercapai, sehingga peran dosen sangat dibutuhkan salah satunya untuk menjembatani antara program studi asal mahasiswa dengan program studi lain atau lembaga non perguruan tinggi selama mahasiswa melaksanakan program MBKM (Sari, 2021). Melihat berbagai peran dosen tersebut, nampaknya merupakan keharusan untuk seluruh tenaga pengajar agar memahami dan mengetahui bagaimana kebijakan MBKM dijalankan.

Mahasiswa sebagai sasaran utama program MBKM ini minim pengetahuan tentang kebijakan merdeka belajar, sebuah penelitian menujukkan bahwa siswa merasa pembelajaran MBKM belum maksimal karena masih dilakukan secara online (Kamalia \& Andriansyah, 2021). Seharusnya pemahaman tentang MBKM ini bukan hanya dimaksimalkan oleh dosen, tetapi mahasiswa harus diberi sosialisasi tentang program MBKM ini karena mahasiswa yang akan menjadi pelaku utama dalam berbagai program yang disediakan seperti magang, pertukaran pelajar dan lain-lain. 


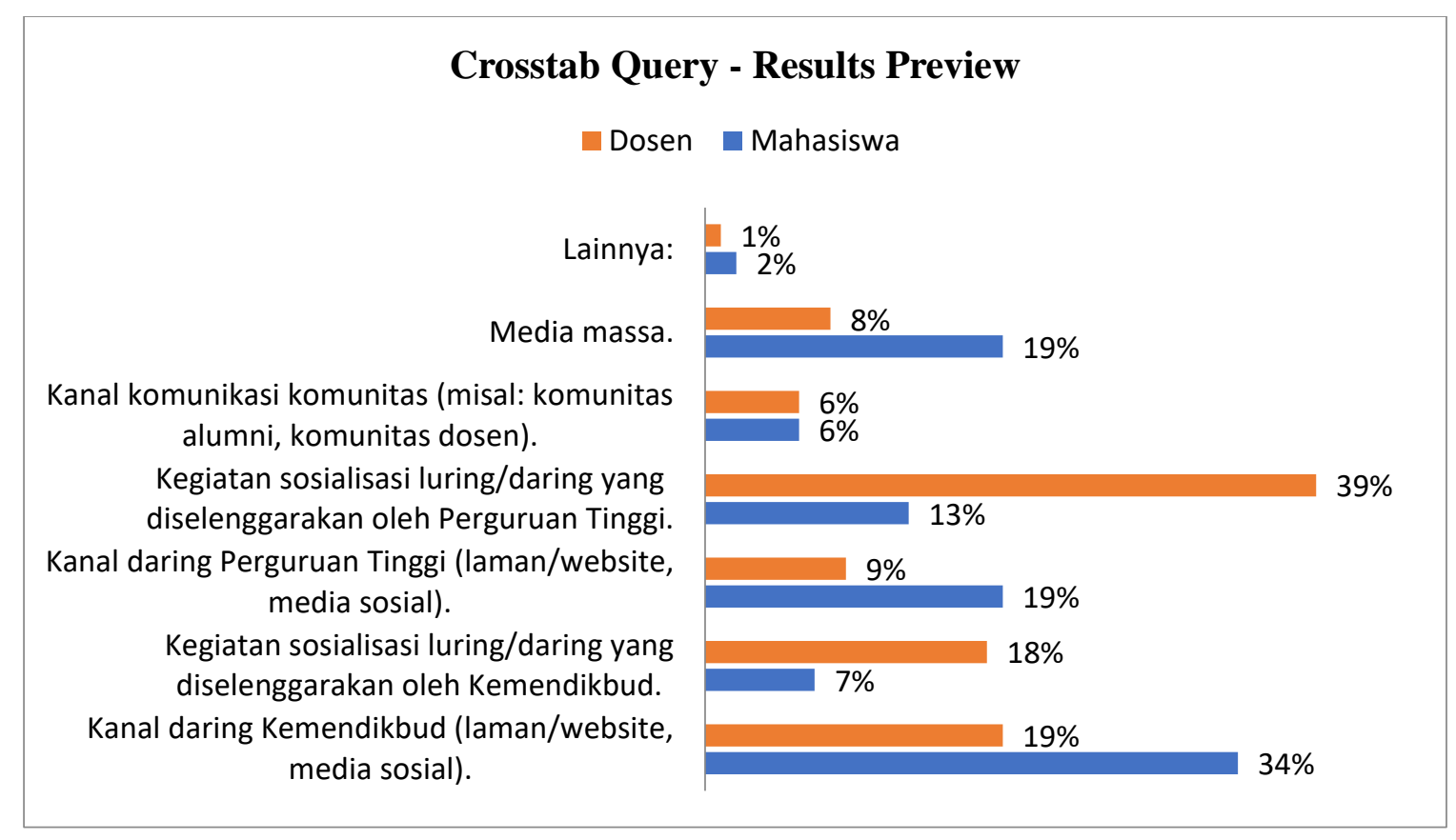

Gambar 2. Sumber Informasi Mengenai Kebijakan MBKM

Sumber: Data Diolah oleh Penulis (2021)

Data pada gambar 2 menunjukkan bahwa perbedaan sumber informasi antara dosen dan mahasiswa terlihat jelas pada saluran yang digunakan, dosen paling banyak mendapatkan informasi melalui Kegiatan sosialisasi baik luring maupun daring yang diselenggrakan oleh perguruan tinggi dengan persentase 39\%, sementara itu mahasiswa yang memiliki pemahaman yang rendah mendapatkan informasi yang dominan didapatkan melalui kanal daring Kemendikbud baik melalui media sosial maupun website dengan presentasi 34\%. Jadi mahasiswa masih perlu dilibatkan langsung dalam pertemuan atau sosialisasi tentang Kebiajakan MBKM karena berdasarkan hasil jejak pendapat mahasiswa yang mendapatkan informasi melalui kegiatan sosialisasi yang diadakan perguruan tinggi hanya $13 \%$. Mahasiswa sejatinya harus mempunyai pemahaman yang paling baik dalam menelaah kebijakan program MBKM, karena kompetensi mahasiswa harus relevan sebagai akibat dari kemajuan teknologi yang pesat dan perubahan sosial, budaya, dan kehidupan kerja (Coccoli, Guercio, Maresca, \& Stanganelli, 2014). Maka tuntutan diseminasi kebijakan harus menyeluruh kepada semua pihak, terutama untuk dosen dan mahasiswa agar program MBKM dapat mudah dipahami dan diaplikasikan sesuai dengan tujuannya.

Mahasiswa sebagai sasaran utama dalam implementasi kebiajakan MBKM memiliki ketertarikan yang cukup baik terhadap kegiatan yang dilakukan diluar program studi, dari 8 (delapan) bentuk kegiatan pembelajaran di luar program studi mahasiswa yang sudah terlaksana didapatkan hasil paling banyak memilih magang/praktik kerja (gambar 3) yang sejatinya merupakan kegiatan yang sedari dulu telah dilakukan oleh perguruan tinggi swasta/negeri. 


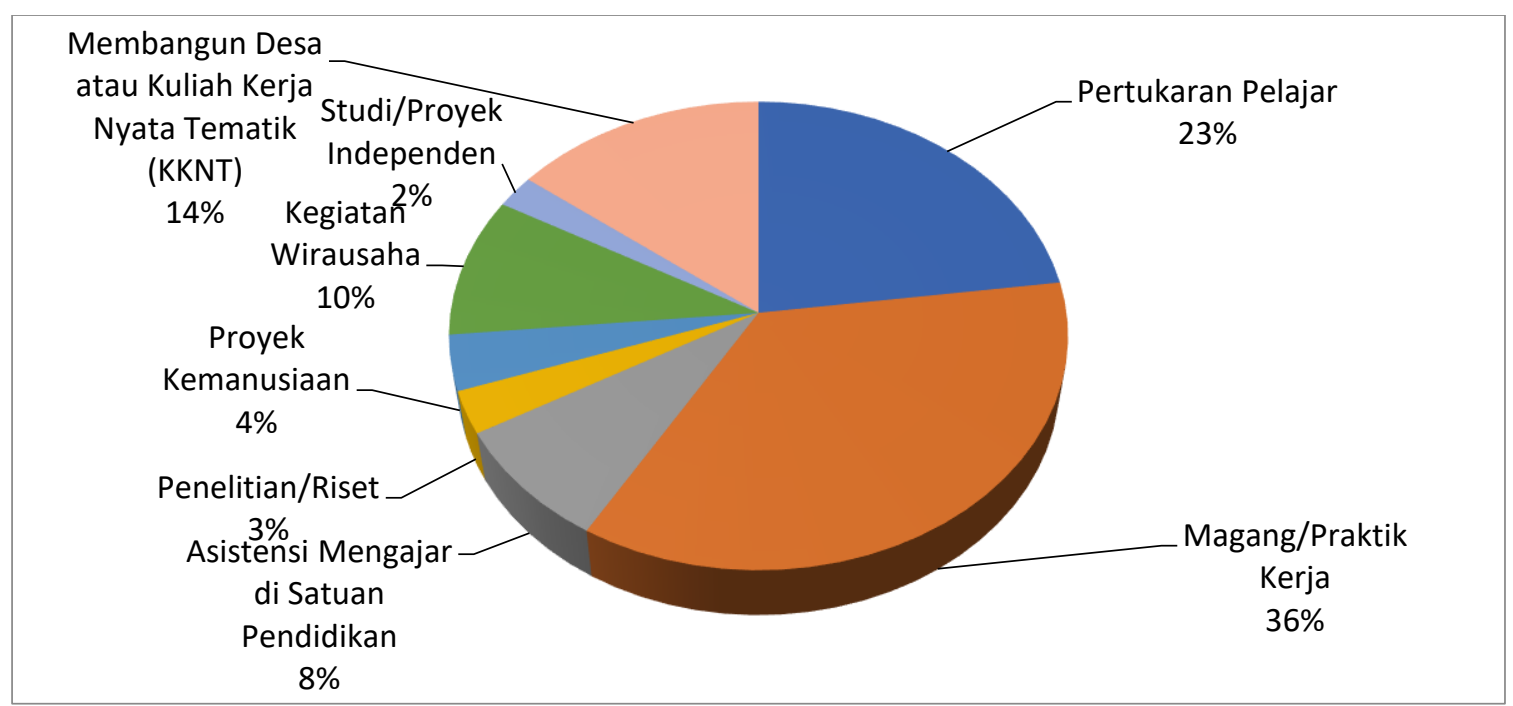

Gambar 3. Bentuk Kegiatan Pembelajaran Di Luar Program Studi yang Diminati Mahasiswa

Sumber: Data Diolah oleh Penulis (2021)

Pilihan bentuk kegiatan yang dipilih mahasiswa diluar program studi sangat beragam, pada penelitian ini mahasiswa dominan memilih program Magang/Praktik Kerja sebagai pilihan kegaiatan di luar program studi dengan presentase 36\%, kemudian Program kegiatan yang lain yang banyak dipilih mahasiswa adalah Pertukaran pelajar 23\% dan Membangun desa/KKN Tematik 14\%. Sementara itu program penelitian/riset ternyata masih belum terlalu diminati oleh mahasiswa dengan tingkat keterpilihan hanya 3\%, padahal program penelitian/riset merupakan salah satu kegiatan yang bisa dilakukan dengan kolaborasi dosen dan mahasiswa dalam membuat sebuah karya ilmiah.

Magang/Praktik Kerja dan Pertukaran pelajar menjadi kegiatan yang paling diminati mahasiswa pada Program MBKM, hal ini tentu saja merupakan sesuatu yang relevan dengan tujuan pemerintah menerapkan Merdeka belajar-Kampus Merdeka. Pemerintah melalui MBKM bertujuan untuk menurunkan angka pengangguran nasional dengan menyelaraskan pendidikan dengan dunia kerja dan industri, memastikan lulusan perguruan tinggi siap bekerja di bidang kompetensi dan memenuhi tuntutan dunia kerja. (Arifin \& Muslim, 2020). Jadi dengan melihat relevansi antara minat mahasiswa dengan tujuan pemerintah dalam program MBKM maka sejatinya penerapan kebijakan Merdeka Belajar-Kampus Merdeka akan menjadi angin segar dalam mencapai tujuan strategis pendidikan nasional.

\section{Pemahaman Tenaga Pendidik Tentang Kebijakan MBKM}

Kebijakan Merdeka Belajar-Kampus Merdeka (MBKM) telah diterapkan diberbagai perguruan tinggi, pemahaman tenaga pendidik tentu saja merupakan hal yang sangat penting untuk keberlangsungan program merdeka belajar kampus merdeka. Melalui Merdeka Belajar- Kampus Merdeka, para sivitas akademika terkhusus tenaga kependidikan di kampus akan menjadi fasilitator bagi mahasiswa untuk memperluas wawasan dan ruang belajar sesuai minat dan keterampilannya. Hasil penelitian pada perguruan tinggi swasta di Kota Makassar menunjukkan bahwa pemahaman tenaga pendidik tentang kebijakan Merdeka Belajar-Kampus Merdeka (MBKM) masih sangat minim, sebagian besar tenaga pendidik hanya sedikit mengetahui tentang kebijakan tersebut, bahkan tenaga pendidik yang belum mengetahui sama sekali mempunyai presentasi yang tinggi. 


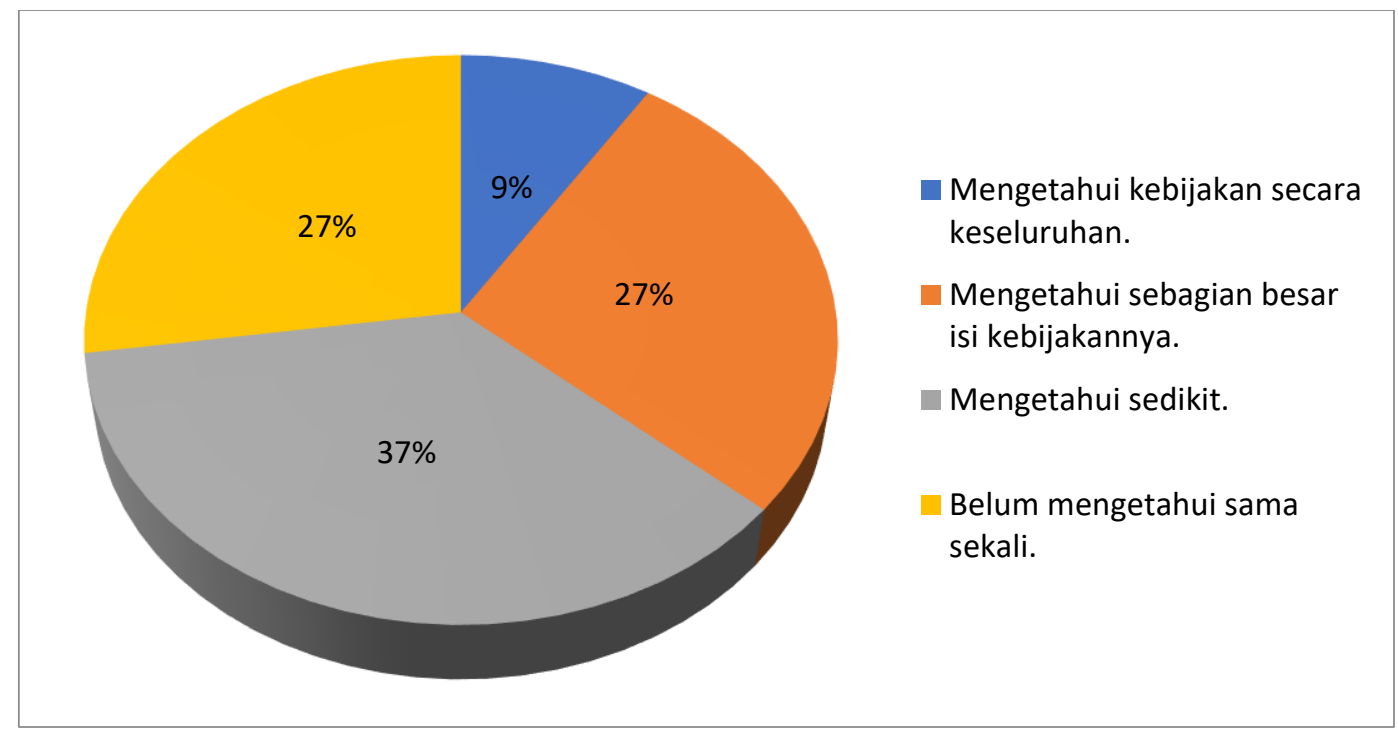

Gambar 4. Pemahaman tenaga pendidik tentang kebijakan MBKM

Sumber: Data Diolah oleh Penulis (2021)

Pada data di gambar 4 menujukkan bahwa diseminasi kebijakan Merdeka BelajarKampus Merdeka (MBKM) masih perlu dimaksimalkan, karena masih banyak tenaga pendidik yang belum mengetahui hakikat dari kebijakan merdeka belajar kampus merdeka, 37\% tenaga pendidik hanya mengetahui sedikit tentang program MBKM, sementara itu $27 \%$ tenaga pendidik yang belum mengetahui sama sekali bagaimana program ini, dan tenaga pendidik yang mengetahui secara keseluruhan hanya 9\%. Hasil tersebut menandakan bahwa Kebijakan Merdeka Belajar-Kampus Merdeka belum sepenuhnya dimengerti oleh tenaga pendidik, sehingga diseminasi kebijakan MBKM masih perlu dimasifkan agar seluruh tenaga pendidik dapat memahami program ini secara keseluruhan. Diseminasi informasi ke publik dengan edukasi terkait kebijakan dan program pemerintah yang dilaksanakan bisa dilakukan dengan memanfaatkan saluransaluran komunikasi yang tersedia (SM \& Narti, 2021).

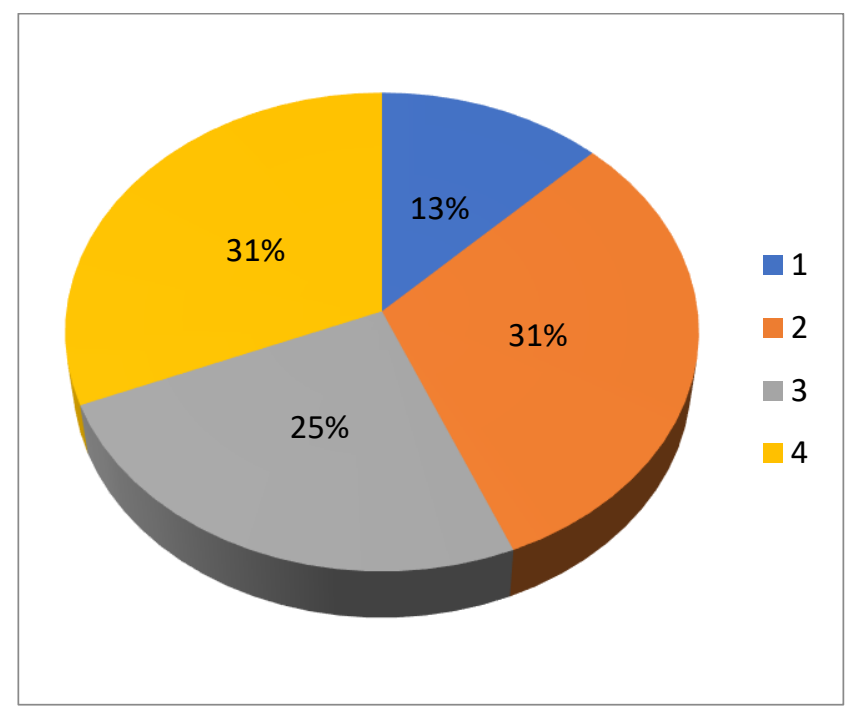

Gambar 5. Jawaban Tenaga Pendidik Tentang Berapa Semester Yang Dapat Digunakan Untuk Melakukan Kegiatan MBKM di luar Perguruan Tingginya

Sumber: Data Diolah oleh Penulis (2021) 
Dari gambar pada gambar 5 memperlihatkankan bahwa pemahaman tenaga pendidik memang masih minim tentang program MBKM, pertanyaan sederhana tentang berapa semester yang dapat ditempuh mahasiswa di luar perguruan tinggi asal hanya $31 \%$ yang menjawab benar ( 2 Semester), jadi ada $69 \%$ tenaga pendidik yang menjawab tidak tepat. Pemahaman tenaga pendidik yang masih minim tentang MBKM tentu saja akan meberikan dampak terhadap tujuan strategis pendidikan dengan kebijakan Merdeka Belajar-Kampus Merdeka. Pelaksanaan program pendidikan yang dilaksanakan untuk mencapai arah gemilang pendidikan harus sesuai dengan kebijakan dan strategi jitu pendidikan yang telah diterapkan dan tidak dilakukan dengan secara mendadak agar berdampak baik pada capaian strategi pendidikan (Fajriyah, Nadhiroh, Mawardani, \& Ainiyah, 2021). Capaian tujuan pendidikan dari program MBKM akan maksimal jika kebijakan ini dapat dipahami dengan baik oleh tenaga pendidik yang merupakan pelayan akademik mahasiswa di Perguruan Tinggi.

\section{Kesimpulan}

Dosen dan mahasiswa merupakan aktor utama dalam penerapan kebijakan Merdeka Belajar-Kampus Merdeka (MBKM). Melalui diseminasi kebijakan MBKM akan mempermudah dosen dan mahasiswa mendapatkan pemahaman tentang program Merdeka Belajar-Kampus Merdeka. Pengetahuan Dosen tentang kebijakan MBKM lebih besar dibandingkan Mahasiswa, dosen sebagai tenaga pengajar lebih mengetahui sebagian besar isi kebijakan MBKM, sementara itu mahasiswa sebagai sasaran utama program MBKM ini minim pengetahuan tentang kebijakan merdeka belajar. Diseminasi kebijakan Merdeka Belajar-Kampus Merdeka (MBKM) masih perlu dimaksimalkan, karena masih banyak tenaga pendidik dan mahasiswa yang belum mengetahui hakikat dari kebijakan merdeka belajar kampus merdeka. Pada Program Merdeka Belajar-Kampus merdeka kegiatan Magang/Praktik Kerja dan Pertukaran pelajar yang paling diminati mahasiswa pada Program MBKM, hal ini tentu saja merupakan sesuatu yang relevan dengan tujuan pemerintah menerapkan Merdeka belajar-Kampus Merdeka yaitu sinkronasi pendidikan dengan dunia kerja dan industri.

\section{Daftar Pustaka}

AlYahmady, H. H., \& Al Abri, S. S. (2013). Using Nvivo for Data Analysis in Qualitative Research. International Interdisciplinary Journal of Education, 2(2), 181-186. https://doi.org/10.12816/0002914

ARIFIN, S., \& MUSLIM, M. (2020). TANTANGAN IMPLEMENTASI KEBIJAKAN "MERDEKA BELAJAR, KAMPUS MERDEKA" PADA PERGURUAN TINGGI ISLAM SWASTA DI INDONESIA. JURNAL PENDIDIKAN ISLAM ALILMI, 3(1). https://doi.org/10.32529/al-ilmi.v3i1.589

Arifin, S., \& Muslim, M. O. H. (2020). Tantangan Implementasi Kebijakan "Merdeka Belajar, Kampus Merdeka" pada Perguruan Tinggi Islam Swasta di Indonesia. Jurnal Pendidikan Islam Al-Ilmi, 3(1).

Baharuddin, M. R. (2021). Adaptasi Kurikulum Merdeka Belajar Kampus Merdeka (Fokus: Model MBKM Program Studi). Jurnal Studi Guru Dan Pembelajaran, 4(1), 195-205. Retrieved from https://www.e-journal.my.id/jsgp/article/view/591

Coccoli, M., Guercio, A., Maresca, P., \& Stanganelli, L. (2014). Smarter universities: A vision for the fast changing digital era. Journal of Visual Languages \& Computing, 25(6), 1003-1011.

Creswell, J. W. (2012). Metode Penelitian Kualitatif. Yogyakarta: Pustaka Pelajar. 
Fajriyah, A., Nadhiroh, C., Mawardani, T., \& Ainiyah, B. N. (2021). Evaluasi Keberhasilan Program Pertukaran Mahasiswa Inbound Outbound Antara Prodi Administrasi Pendidikan FIA UB Dan Manajemen Pendidikan FIP Unesa.

Harakan, A. (2017). Efektivitas pelaksanaan kebijakan sistem kelas tuntas berkelanjutan di kabupaten Gowa. Aristo, 5(1).

Kamalia, P. U., \& Andriansyah, E. H. (2021). Independent Learning-Independent Campus (MBKM) in Students' Perception. Jurnal Kependidikan: Jurnal Hasil Penelitian Dan Kajian Kepustakaan, 7(4), 857-867.

Krisnanik, E., Saphira, Q., \& Indriana, I. H. (2021). Desain Model MBKM Dan Kolaborasi Kerja Sama Model Pentahelix Guna Meningkatkan Daya Saing Lulusan. Proceeding KONIK (Konferensi Nasional Ilmu Komputer), 5, 138-142.

Leuwol, N. V., Wula, P., Purba, B., Marzuki, I., Brata, D. P. N., Efendi, M. Y., ... Sari, I. N. (2020). Pengembangan Sumber Daya Manusia Perguruan Tinggi: Sebuah Konsep, Fakta dan Gagasan. Medan: Yayasan Kita Menulis.

Mariati, M. (2021). Tantangan Pengembangan Kurikulum Merdeka Belajar Kampus Merdeka di Perguruan Tinggi. Seminar Nasional Teknologi Edukasi Dan Humaniora 2021, Ke-1, 747-758. CERED.

Miles, M. B., \& Huberman, A. M. (2007). Analisis Data Kualitatif: Buku Sumber Tentang Metode-Metode Baru. Jakarta: Universitas Indonesia Press.

Ningrum, E. (2016). PENGEMBANGAN SUMBER DAYA MANUSIA BIDANG PENDIDIKAN. Jurnal Geografi Gea, 9(1). https://doi.org/10.17509/gea.v9i1.1681

Saleh, M. (2020). Merdeka belajar di tengah pandemi Covid-19. Prosiding Seminar Nasional Hardiknas, 1, 51-56.

Sari, I. N. (2021). MEMERDEKAKAN DOSEN MELALUI PENINGKATAN PERAN DALAM PROGRAM MERDEKA BELAJAR KAMPUS MERDEKA. In Dosen Merdeka. UNISMA PRESS.

Sarnoto, A. Z. (2013). Konsepsi politik pendidikan di Indonesia. Jurnal Educhild: Pendidikan Dan Sosial, 1(1), 30-40.

Siregar, N., Sahirah, R., \& Harahap, A. A. (2020). Konsep Kampus Merdeka Belajar di Era Revolusi Industri 4.0. Fitrah: Journal of Islamic Education, 1(1), 141-157. https://doi.org/10.53802/fitrah.v1i1.13

SM, A. E., \& Narti, S. (2021). FUNGSI MEDIA CENTER SEBAGAI MEDIA DISEMINASI INFORMASI PEMERINTAH DAERAH KOTA BENGKULU. Professional: Jurnal Komunikasi Dan Administrasi Publik, 8(1), 37-43.

Soeprapto, S. (2013). Landasan aksiologis sistem pendidikan nasional Indonesia dalam perspektif filsafat pendidikan. Jurnal Cakrawala Pendidikan, 32(2).

Sopiansyah, D., \& Masruroh, S. (2022). Konsep dan Implementasi Kurikulum MBKM (Merdeka Belajar Kampus Merdeka). Reslaj: Religion Education Social Laa Roiba Journal, 4(1), 34-41. https://doi.org/10.47467/reslaj.v4i1.458

Woolf, N. H., \& Silver, C. (2017). Qualitative analysis using NVivo: The five-level QDA® method. London: Routledge. 